\title{
The Use of Linkedin as a Recruitment Tool in the UAE: An Evaluation
}

\author{
I. Ismail and S.Koshy
}

\begin{abstract}
This study looks at the use of LinkedIn in the United Arab Emirates. In-depth interviews with representatives of five organisations and five recruitment companies based in the UAE were conducted to evaluate the use of LinkedIn as a recruitment tool. The study showed that LinkedIn is a cost effective recruitment tool. It is efficient when looking for candidates at the senior level or for those with specialized and unique skills. Recruitment agencies also see it as a competitor. The study concluded that to use LinkedIn effectively organisations should have a clear social media strategy.
\end{abstract}

Index Terms - LinkedIn, social media, recruitment, UAE.

\section{INTRODUCTION}

$\mathrm{T}$ he UAE is one of the most developed countries in the Middle East where internet penetration is very high and social media platforms are subscribed to in massive numbers. Many studies have been done on Twitter, Facebook, Instagram and LinkedIn as marketing tools and how they can be used by organisations worldwide and in the Middle East. This study focuses on the efficacy of LinkedIn as a recruitment tool in the UAE.

LinkedIn is considered the number one recruitment portal worldwide, but is yet to gain that status in the UAE. A study of the efficiency of using LinkedIn as a recruitment source will help in making a decision whether to consider it in recruiting and in looking for a job. The purpose of this study is to figure out the efficiency of LinkedIn in recruiting in the UAE and to find out HR managers' and recruitment companies' perception of LinkedIn as a recruitment portal. A comparis on between the traditional recruitment methods verses LinkedIn recruitment will be discussed.

\section{USE OF SOCIAL MEDIA IN BUSINESS}

Social media can be defined as creation of text, pictures, and video for sharing through online platforms [1]. With the

Manuscript $\square$ received 18/02/2017.

I. Ismail is a graduate of Master of Media and Communications at the University of Wollongong in Dubai (e-mail: iman.lotfii@gmail.com ).

S. Koshy is Associate Professor, Arts and Humanities at the University of Wollongong in Dubai, Dubai, UAE. (e-mail: swapnakoshy@uowdubai.ac.ae), development of smartphones in 2000 and third generation of mobile telecommunications technology in 2002, social media invaded the market with its different platforms; like Facebook,

Twitter, LinkedIn, YouTube, Google+, Instagram and Pinterest.

Social media platforms are used by business organisations for different purposes including customer support, brand reputation and management, product feedback polling, product promotion, leads generation, news distribution, establishing public relations and networking [2]. The marketers considered Facebook and LinkedIn as the most significant social platforms; $54 \%$ of marketers preferred Facebook and 17\% LinkedIn.

\section{SOCIAL MEDIA USAGE IN THE UAE H}

In 2012, the number of individuals who visited social media sites at least once daily increased by $19.2 \%$ from 2011 , it was predicted to increase to $63.2 \%$ in 2013 and $70.7 \%$ in 2014. One out of every four people in the world will use a social network in 2014 [1].

A pan Arab research by the Mohammed Bin Rashid School of Government states that Facebook has the highest number of users with $91 \%$, followed by Google+ with $69 \%$, YouTube with $60 \%$, Twitter with $57 \%$, LinkedIn with $36 \%$ and Instagram with $22 \%$ users [3].

The Arab Media Outlook (2011-2015) found that over $65 \%$ of the population in the UAE has a smartphone and about $78 \%$ own a laptop. This makes it more convenient for people to access social media platforms. Facebook Arabic and Facebook English are the most visited social networking sites, followed by Google+ and Twitter in English and Arabic. LinkedIn, however, is visited less frequently. The reason can be that LinkedIn is available in twenty three languages but not in Arabic. [4].

\section{HUMAN RESOURCES AND RECRUITMENT}

The role of human resource management is to plan, develop, and regulate policies to effectively utilise human resources and maximise individual development. The major functional areas in human resource management can be listed as: planning, staffing, employee development and employee maintenance; the core function is staffing and employee development [5]. Staffing, involves recruitment and selection of the human 
resources for the organisation. Human resources planning and recruiting come before the actual selection of people to fill the vacancies available.

For the purpose of this research, we will focus on recruitment which is a vital function and a competitive strength. The objective of the recruitment process is to hire quality employees to help the organisation achieve its goals. Recruitment creates a pool of prospective employees for the organisation ready to select the right candidate for the right job. As defined by Edwin B. Flippo (1984), "Recruitment is a process of searching for prospective employees and stimulating them to apply for jobs in an organisation". [6]

Recruitment needs can be classified into three categories; planned as per the changes in the organisation chart and retirement policy, anticipated due to transfers studying the internal and external environment and unexpected due to resignation, deaths, accidents, and illness of the current employees [5]. The recruitment process is systematic, starting with vacancy identification, job description, vacancy marketing, controlling applications, shortlisting, arranging interviews, and decision making.

\section{PASSIVE VS. ACTIVE CANDIDATES}

Passive and active candidates are common terms in recruitment. Active candidates are candidates who are actively looking for a new opportunity, whether they are employed or not. The best way to approach this category is through job postings with matching keywords. Recruiters may receive a large number of applications by unqualified candidates. This is why LinkedIn offers sourcing solutions; LinkedIn Talent Solutions. Passive Candidates are those who are employed and not looking for a new job. This category forms about $75 \%$ of the workforce. The best way to find this category of candidates is through proactive sourcing (Boolean searches, social media, etc). Also, referrals can be an effective tool to approach them [7]

\section{RECENT TRENDS IN RECRUITMENT}

Recruitment agencies or intermediaries are experiencing a dramatic increase in demand both from employers and job seekers. They save the organisation's time and effort in posting vacancies, looking into not fitting resumes, and arranging fruitless interviews. However, lately, recruitment agencies and consultants are facing a tough competitor, erecruitment. Knowledge of the market and the candidates helps recruitment intermediaries or agencies to offer services at competitive prices.

\section{E- RECRUITMENT}

E- recruitment, also known as online recruitment, is the use of technology in the recruitment process. E-recruiters publish job vacancies on the Internet. The job seekers send their applications or curriculum vitae through email or online portals, like naukrigulf.com, bayt.com, jobs.abudhabi.ae, social media platforms, the organisation's web site or its own intranet. A study of 2001 internet users in the US found that "among Americans who have looked for work in the last two years, $79 \%$ utilized online resources in their most recent job search and $34 \%$ say these online resources were the most important tool available to them." [8] The study also found that "eight-inten Americans ages 18 to 29 have researched (83\%) as well as applied for a job (79\%) online. However, a substantial majority of those ages 30 to 49 (and a sizeable minority of those ages 50 to 64) have engaged in these behaviors as well." That the internet is definitely a popular place for e-recruitment as there are more than 40 million resume's floating online. [9]

The advantages of this type of recruitment are the low cost, dispensing off intermediaries, shorter turnaround time and the 24/7 access to millions of online resumes. On the other side, the disadvantages of e-recruitment are the time consuming process of screening and checking millions of res umes, the fact that not everyone is online, and the lack of face-to-face interaction [10].

A study titled, "Recruitment via Social Networking Sites" conducted by Silke Wesselink (2012) discusses the impact of social networking on recruitment in comparison with the traditional recruitment in the light of related studies. The study concludes that traditional face to face recruitment is better and has greater influence on potential candidates [11]. However, in line with media richness theory that states that communications via more natural/ rich media channels have greater impact than communication sent via less natural/ less rich media channels Kaplan and Haenlein (2010) assert that erecruitment sites are media rich. [12]

'Internet Recruiting Power: Opportunities and Effectiveness' by Pim et al (2001) found that e-recruitment saves time and increases the chances of hiring the right candidate. In 'Investigating web-based recruitment sources: Employee testimonials vs word-of-mouse' the authors found that a benefit to the job seeker is that the company profile is shared online with more transparency than with the traditional job advertisements. [13].

\section{LINKEDIN AND RECRUITME}

LinkedIn is considered the future number one recruiting portal according to ERE.net (2012). It was founded by Reid Hoffman, Allen Blue, Konstantin Guericke, Eric Ly and JeanLuc Vaillant. LinkedIn was officially launched on May 5, 2003. It is headquartered in US with offices in US and in 27 cities around the world and only Dubai in the UAE in the Arab World. Dubai got the Global Membership on August 5, 2014.

After one month in operation, 4,500 users joined LinkedIn. Now, it is "the world's largest professional network with more than 400 million members in 200 countries and territories around the globe." Professionals are joining LinkedIn at a rate of more than two new members per second. [14]. 
The way business is operated is changing. Professionals need to make decisions faster and based on rigorous research. With LinkedIn, they can build their professional profiles and get connected to have a better insight into the professional world. It also helps in the hiring process. Recruiters can find, engage and hire passionate and experienced candidates. By making recruiting easier and more competitive LinkedIn made a revolution in the recruitment field. It collects more than 250 million curricula vitae helping companies in hiring. [15] Dan Shapiro, senior vice-president for global solutions at LinkedIn announced at tft.com, "LinkedIn would develop algorithms akin to those Google has created for its search engine, using its large database to find the right candidates with the aim of transforming the "incredibly inefficient" world of recruiting and charting careers" [15]. However, LinkedIn is not without problems. Employment Office managing director Tudor Marsden-Huggins warns "it's becoming increasingly common for people to lie about or exaggerate their skills and experience on their LinkedIn profile" [16].

According to businessinsiders.com, one in six employees uses social networking sites when looking for a job. Nearly $90 \%$ of people looking for a job have an account on a social media platform; $54 \%$ of them are on Facebook, Twitter, and LinkedIn. In 2011, 50\% of job hunters used Facebook, 25\% used Twitter, and 36\% used LinkedIn. Facebook is a very competitive platform; in a study done on Americans, about 18.4 million got their current jobs through Facebook; 10.2 million through Twitter and 8 million through LinkedIn. [17] But, LinkedIn has the exclusivity of owning the professional identity of its users. In 2012, revenue from its hiring solutions composes more than half of total revenue (South Asian Media Net, 2012). It relied on the big demand on its recruitment products. There was an unexpected increase in revenue and net income the second quarter of 2013 [18].

In 2013, the top five countries with the largest number of users were USA with 58.8 million users, India with 13.3 million users, UK with 8.4 million users, Brazil with 6.8 million users and Canada with 5.1 million users. Analysing the users, $44 \%$ of the users are employed by big companies with minimum 10,000 employees; 39\% occupy high-level managerial posts including directors, chief officers, and vice presidents. In the global market, the most represented industries are high-tech at $14.3 \%$ finance industry at $12.4 \%$ and manufacturing at $10.1 \%$. From a different perspective, as per another survey was done on LinkedIn users, the male to female ratio is $50 / 50.81 \%$ of the users are aged $35+$ and $19 \%$ aged up to 24 . Most of them, $87 \%$, are educated to college or degree level [1].

\section{LINKEDIN IN THE ARAB WORLD}

LinkedIn is becoming more common in the Arab World. Farhan Syed, the director of global sales strategy at LinkedIn said to The National, "There are over a million of those members here in the United Arab Emirates, and greater than five million members currently in the Middle East. Every second of every day, two new members join LinkedIn. And we're excited to see that growth continue globally, and especially here in the Middle East". [19].

Deep Nishar, LinkedIn's SVP of product \& user experience confirmed his colleague, Syed's announcements and added, "The IT sector contributed to the big growth with 4 million members, followed by services sector with two million and higher education with 1.95 million members". The numbers announced can be seen as big figures to LinkedIn but compared to Facebook, Twitter and Google + the numbers are very small. He said that "networking site is growing as more professionals join the network but no one knows who many are active". [20].

The frequency of LinkedIn usage in the Arab World was surveyed recently by Dubai School of Government (DSG, 2013). While $65 \%$ never accessed LinkedIn, the percentage of users who access it once a month is $6 \%$, those who access it more frequently, 2 to 3 times a month is $4 \%$, the same percentage of users access it once a week and the percentage increases to $8 \%$ for those who access it more frequently in a week 2 to 4 times and $14 \%$ of the users access at least once daily. [21] LinkedIn is now accessible everywhere not on desktops and laptops only; it is accessed on iPhone, iPad, Android, Windows Phone, BlackBerry; $45 \%$ of the members are accessing on mobile. [14]

\section{The USE OF LINKEDIN IN THE UAE}

In the UAE the recruitment levels in the country has been increasing in 2011 compared to the past years. Peter Greaves, Director, Head of Financial Markets at McArthur Murray, Dubai, announced in Emirates 24|7, that "15\% new jobs" were created in the beginning of the first quarter. [22] The job market in the UAE is becoming more vivid as organisations are expanding and new entities are opening. This movement is supported and enhanced by Tawdeef, a vital recruitment event in the region. Chris Fountain, Director of Tawdheef and Managing Director of Turret Media, commented on the event "Companies continue to positively achieve sustainable economic growth and social inclusion objectives, as outlined in the Abu Dhabi Economic Vision 2030, giving a more positive outlook of the region's recruitment market". [23] The progress has been steady throughout the years. Christopher Greaves, Managing Director at recruitment consultancy Hays - Gulf Region also confirmed the rise the hiring activity. Gareth Clayton, Director at recruitment consultancy Charterhouse Middle East, agreed with Clayton and backed himby saying, "Demand levels are strong and consistent whilst showing a good improvement on the recessionary period of the past few years, " concluding with "recruitment in the UAE is not back to the dizzy heights of 2007 and 2008”. [24]

As a continuation of this success and to retain the increasing levels of recruitment, seminar sessions were held in 
2013 to bring human resources professionals together to study the most recent trends in the recruitment sector in the Middle East. The seminar highlighted the role the social media can play in the recruitment filed insisting on the need of developing new social media strategy integrating the new technologies and re-formulating business processes. Lynne Bellinger, Managing Director UAE for Purple Cubed commented "We also actively research a candidate's online presence such as their LinkedIn profile or Twitter feed, as this gives additional invaluable insight". [25]

In 2014, LinkedIn listed Etihad Airways, Emirates Airline, Jumeirah Group, Cleveland Clinic Abu Dhabi, Emaar, Etisalat, National Bank of Abu Dhabi, Du, Damac and TASC as the most influential brands in the UAE in terms of the number of engaged members. [27]

\section{Methodology}

The study focuses on recruitment in Abu Dhabi and Dubai, as they are the more vital markets in the UAE. It analyses the market based on studies done on five recruitment agencies and five HR specialists. Qualitative analys is of in-depth interviews using a structured survey instrument has been done. Those interviewed include HR managers in leading UAE companies (NPCC, Etisalat, Tawazun, Department Of Municipal Affairs in Abu Dhabi, and News Group International in Dubai) and recruitment companies in the UAE (Reach Group, PinPoint HR, Horizon International Recruitment Services, Al Qabas Employment and Exceed IT services ). Some Interviews were face-to-face and others were done through the phone. The questions were based on themes including efficiency of LinkedIn, company policy on use of LinkedIn and RoI. All interviews were recorded and transcribed. Nvivo was used to qualitatively analyse the data. Secondary data was collected from websites, social media platforms, journals, books and published research.

\section{LARGE COMPANIES VS. SMALL COMPANIES}

Big companies with 5000+ employees do have their own database from their own website at their server. The have wellstructured websites. So, they use their own portals as a database when looking for candidates. As they are wellrecognised, they have many applicants; this is the case with Etisalat, Tawazun and NPCC. Others like News Group International and Department of Municipal Affairs, use their main database to received CVs by email and use online recruitment portals and headhunting. Another unique practice in big companies is that they prioritise internal transfer options; looking for candidates within the organisation. Also, the have a large number of employees so referrals is another major source of recruitment before going to recruitment agencies or LinkedIn.

\section{RECRUITMENT AgENCIES}

The recruitment agencies, though, of small size, all need to have their own database of CVs, which are well-organised and easier to filter. All recruitment companies are using their own website as a major recruitment source with as many features as is affordable. So, social media can be used for marketing and traffic direction to the website more than as a recruitment tool.The website application is beneficial if it is integrated with software for filtration technique. It saves time and efforts. All recruiters agreed that for headhunting, LinkedIn is the best. Since the website cannot get the profile of passive candidates.

\section{DAT A ANALYSIS}

\section{A. Efficiency}

The efficiency of using LinkedIn can be measured by the time and the cost of finding the best match for a job vacancy. All participants agreed that online recruitment is more efficient than the traditional recruitment method. It is easier and cheaper with wider database. It lacks face-to-face interaction but as a first point of contact to search for a candidate who matches a specific job vacancy, it is efficient. It saves the paper work and time consumed and looking through a pile of CVs.

All companies agreed that the LinkedIn is efficient and the best tool to look for passive candidates at the senior level and with hard-to-find technical specialty. Aya Al Bateeh, HR officer at Department of Municipal Affairs, states "LinkedIn is the best platform to get in touch with candidates especially in majors like Geographical Information System, HSE, audit and IT Security where candidates are satisfied at their current jobs and they are not applying for jobs with experience of 8 years and above." This level of employees are satisfied at their current job and they are not uploading their CVs on online portals like bayt, naukrigulf and Jobs Abu Dhabi. So, the best way to approach them is through LinkedIn.

Roba Al Kassem, at the recruitment agency, Reach Group, emphasises that. "We usually use the online portal, like naukrigulf to look for candidates at junior level working or looking for a position in sales and administration, but for higher level, we use LinkedIn if we didn't match at our portal."

\section{B. Geographical and Demographical Factors}

The advantage of LinkedIn is that it is not limited by the geographical area.

Government Organis ations:

The geographical factor is not an is sue for the governmental organisations as they must check the local candidates first, like Tawazun, Etisalat, and Department of Municipal Affairs. Their main target is Emiratis. If they can not find candidates with matching skills, they start looking at different sources, including LinkedIn.

Recruitment Companies:

Mohammed Naveed, a Recruitment Professional at Al Qabas 
Recruitment Services, states, "I use all major job portals like Monster, Naukrigulf and Bayt. If it is local recruitment, I would prefer Naukrigulf because they have a good database and it is cost effective. If it is global or overseas recruitment, I would go with Monster or LinkedIn because they are well-known brand and their reach is worldwide."

Roba Kassem, added on this point, "if we are looking for Arabs or Emirati's, we usually use Jobs Abu Dhabi, if we are looking for asians, we go to gulf monster, since they have branches in India."

\section{Expenses}

LinkedIn vs. Recruitment Agencies:

When the companies were asked about the ROI, they did not provide specific figures.

Companies that are planning to expand, they are planning to use LinkedIn as a major recruitment sources as it is considered cost effective. Bindu Ajay, HR Officer at Tawazun, stated 'Currently we are not paying, but may be by the mid of next year as we have big projects.' Same as the Department of Municipal Affairs, they are working on a new organization chart, so, it is expected to have more vacancies throughout this year.

Some companies are dealing with recruitment agencies but still have a recruiter plan on LinkedIn as it is cost effective comparably, its higher ROI. Especially, if the size of the company is big. For example, Etisalat is a very big organisation with more than 10000 employees. When recruiting, they start with internal announcement and referrals, then they look for candidates on their own websites as it is well-structured. After that, LinkedIn is used. If they could not find the right candidates they go to recruitment agencies .

Recruitment companies, on the other side, are spending money on recruiting trips for headhunting, on their website development and subscription in the online recruitment sites. So they are using the free version of the LinkedIn. Employees create their own profiles. The company makes sure that their profiles are presentable. If they needed, they may pay money for premium account, so their recruiter can have access to the contact details of the candidates.

Muna Elderbi, HR recruiter at Exceed IT services, states, 'We don't pay for recruitment talent solutions on LinkedIn. But, we make sure our profile is always upgraded to track all the people who are opening or viewing our page and to be able to see their contact details.'

Recruitment companies usually charge from 18 to 25 percent of the annual salary, as stated by Adil Bilal from Pinpoint HR. So, for big companies like Etisalat this percentage costs them a lot in comparison to the charged of LinkedIn plans; for example, recruiter Lite features cost US\$1,199.40 / year and Business Plus features for US\$575.88 / year. This is considered a big threat to the recruitment agency business .

The company size, the expansion plans, the recruitment agency charges, the efficiency of the recruitment agency, the
LinkedIn subscriptions charges, the financial figures of the companies and the Return On Investment (ROI) factor, all these factors are used to take the decision on whether or not to pay for LinkedIn.

Recruitment companies do not pay LinkedIn because they are already investing on their portal. They consider it its main source of recruitment. If they are looking for someone at senior level, they go to headhunting; either through LinkedIn or Some companies are planning to expand.

\section{Company Policy}

LinkedIn Vs. Other Platforms

Many companies have accounts on LinkedIn, but not on other social platforms; except the big companies, like Etisalat, Tawzun and Department if Municipal affairs are very active on social media and have a plan. Social media account are managed by Business Development Department, Marketing Department or Public Relations Department depending on the organis ational chart.

They use LinkedIn as a recruitment, marketing, and business development tool. Tawazun uses LinkedIn in searching for candidates but it is not the main source as they are looking for very high level job positions that cannot be found on social media platforms. The Department of Municipal Affairs, for example, are very active on Social media. It is managed by the public relation department. They are not concerned about marketing as a governmental organisation. They used LinkedIn to look for candidates with specific qualifications. They are using Facebook, Twitter and Instagram to promote their organisation as an attractive place to work at.

Aya Al Bateeh, stated, "We mainly use twitter, Instagram and Facebook to market our social environment and promote as an open environment to encourage candidates to join us as an organisation." This goes with the definition of recruitment by Edwin B. Flippo which is "Recruitment is the process of searching the candidates for employment and stimulating them to apply for jobs in the organisation".

Many companies do not have a social media strategy and do not exist on Facebook, Instagram and Twitter but do exist on LinkedIn as a professional platform like NPCC.

Etisalat, on the other hand, is a unique case in this regard. They have a social media department and social media agency, SocialEyez, one of the leading agencies in social media. They are managing their accounts; Facebook, Twitter, Instagram, Youtube and EtisalatUAE LinkedIn Account. Facebook and Twitter for branding, sales and customer services, as well. Instagram for branding and socialising with their clients. Also, whenever fans or followers ask about the chances to join Etisalat, a link to the website is provided. LinkedIn is used for publishing business related articles and product launches. Etisalat is investing in LinkedIn and subscribing to paid services. They have a separate LinkedIn corporate account managed by Etisalat, not the agency. They are using it in recruitment and business development.Through this account, 
they publish vacancies, contacting candidates and providing links in their corporate account to their websites. They are in addition, joining groups, as part of their business development strategy.

As for the recruitment companies, they all agreed that the main use of LinkedIn and social media is recruitment. They are mainly using LinkedIn, most of them as personal profiles to look for candidates with a page to introduce the company. Even their Facebook accounts are purely for posting vacancies. They do not have a social media strategy, they either have their account linked to software to post the vacancies automatically or anyone in the $H R$ or in an administrative role posts to Facebook. They are not concerned about the number of followers or engagement.

\section{E. Training}

Most companies have internal training on LinkedIn, most employees know the basics already. They are familiar with LinkedIn. Only News Group and Etisalat, out of ten attend LinkedIn workshops. Other companies are more concerned with the basics and ensure that the recruiter at their company has a presentable profile. This may be because of the company culture as media, social media and news agency, they are interested in every new technology or features in the media field.

\section{F. LinkedIn Reliability}

None of the interviewees doubted the credibility of LinkedIn. All LinkedIn account holders have mentioned correct information in their profile. All candidates recruited through LinkedIn were qualified and up to the expectation. The only difficulty is in getting touch with the candidates sometimes.

\section{G. Social Aspects}

LinkedIn is for Networking and it is considered as the first point of contact. After getting in touch with the candidates they communicate privately and with accordance to the HR procedures. The communication is always at the personal level; between the recruiter and the candidate. Socially, on LinkedIn, companies participate in groups for business development purposes. They are using other social media platforms to socialise with candidates motivating them to join the company.

\section{CONCLUSION AND RECOMMENDATIONS}

In general, all participants agreed on the efficiency on LinkedIn as a recruitment tool. The recruiters have their own personal accounts that they use to look for candidates. They claimed that LinkedIn is the best source in recruitment for senior level job vacancies and niche jobs. They all agreed that it is a reliable source and is also trustworthy. LinkedIn is beneficial and cost effective especially when there are organisational expansion plans. Recruitment companies are using social media only for recruitment. Other companies are using social media for recruitment, marketing and business development. Some companies use other platforms to promote the company as an attractive place to work at. Recruitment companies are not paying for LinkedIn. Other companies are paying for LinkedIn and they compare it to the recruitment agencies charges and make decisions based on the ROI. Companies do HR training but rarely LinkedIn training. Most companies are depending on the very basic knowledge of LinkedIn.

It is recommended that companies create a social media strategy and be active on all social media platforsm to best utilise these tools. It is also important to evaluate the use of LinkedIn versus the recruitment agencies costs and calculate the ROI, as this will help in deciding whether or not to pay for LinkedIn. All HR specialists should have frequent training on LinkedIn to use its features in the most efficient and effective way.

\section{REFERENCES}

[1] Carvill M and Taylor D 2013, The Business of Being Social, Crimson Publishing, UK.

[2] Ontario 2013, Social Media for Small Business, retrieved from http://bit.ly/1mSM7ST on 18 Sep 2014.

[3] Mohammed Bin Rashid School of Government, 2014, The Arab World Online 2014: Trends in Internet and Mobile Usage in the Arab Region, retrieved from http://bit.ly/1o1AcS1 on 25 Aug 14.

[4] Bin Fahad M, Ibrahim A, Jarrar S, Sabra M, Qussous S, Mazen M, Al Yousuf N, Matar A, Otaibi L, Saguto S,Araimo A, Hughes J, Elwes T, Durou E, Arora A, Hamadeh L, Sawaya R, Zakarya M, Malak S, Fayad P, (2012) Arab Media Outlook 2011 - 2015, 4th Edition, Dubai Press Club, retrieved from http://bit.ly/1rJTqgg on 14 Sep 2014.

[5] Sahu, R K, 2010, Managing Recruitment Function, 1st Edition, Anurag Jain, New Delhi.

[6] Flippo, E., B., 1984, Personnel Management, Mac Graw Hill, New York.

[7] Picard, J, 2013, Recruiting Active vs. Passive Candidates , retrieved from http://linkd.in/1hHgDWl on 4 Dec 2014.

[8] Smith, A. 2015, 'Searching for Work in the Digital Era', accessed 01/04/2016,

available http://www.pewinternet.org/2015/11/19/searching-for-work-in-thedigital-era/

[9] Bolles, R., N., 2016, What Colour is Your Parachute? Ten Speed Press, USA.

[10] Deillon, C., 2014, "The advantages and challenges of turning towards e recruitment for small and medium sized businesses (SME)", retrieved from http:// bit.ly/1BMenLY on 1 Jan 2015.

[11] Wesselink S.,2012, Recruitment via Social Networking Sites, University of Twente, retrieved from http://bit.ly/1xF111C on 4 Sep 2014 .

[12] https://doi.org/10.1016/j.bushor.2009.09.003 https://doi.org/10.1016/j.bushor.2009.09.003

[13] Van Hoye, G. \& Lievens, F. 2007, Investigating web-based recruitment sources: Employee testimonials vs word-of-mouse, International Journal of Selection and Assessment, 15(4), 372-382. doi:10.1111/j.1468-2389.2007.00396.x https://doi.org/10.1111/j.1468-2389.2007.00396.x

[14] LinkedIn Corporation, 2014, LinkedIn, retrieved from www.Linkedin.com on 1 Sep 2014.

[15] Kuchler H., 2013 LinkedIn sets sights on recruitment trade, ft.com, retrieved from http://on.ft.com/1tiQ6Fh on 20 Sep 2014. 
[16] Jones K.,2013 Is LinkedIn a waste of time?, The Sydney Morning Herald, retrieved from http://bit.ly/Y2Wngz on 23 Sep 2014.

[17] EcoMatters 2011, INFOGRAPHIC: Can Facebook, Twitter And Linkedin Really Get You A Job? , Business Insiders, retrieved from http://read.bi/10lWTHg on 20 Sep 2014.

[18] Dembosky A., 2013, LinkedIn lifted by recruitment product sales: MEDIA, Financial Times, retrieved from http://bit.ly/YU66VT on 19 Sep 2014.

[19] Flanagan B., 2012, A million people are LinkedIn in the UAE, The National, retrieved from http://bit.ly/1oChVWt on 25 Sep 2014.

[20] Cherrayil, N., 2013, Linkedin surpasses $1 \mathrm{~m}$ users in UAE, The Gulf News, retrieved from http://bit.ly/1vwWX0x on 5 Sep 2014.

[21] Dubai School of Government, 2013, The Arab World Online: Trends in Internet Usage in the Arab Region, retrieved from http://bit.ly/1wW0pTf on 2 Sep 2014.

[22] Kapur, S., 2013, UAE may soon have equal holidays for public and private sectors, Emirates247, retrieved from http://bit.ly/1rLEAW2 on 5 Sep 2014.

[23] WAM, 2011, Recruitment in UAE gains ground, Khaleej Times, retrieved from http://bit.ly/1nQ2JeM on 4 Sep 2014.

[24] Cornwell A., 2013, "UAE recruitment levels increasing", The Gulf News, retrieved from http://bit.ly/1sOu0A4 on 5 Sep 2014.

[25] Arabian Travel Market 2013, Recruitment and retention under spotlight at Arabian Travel Market, retrieved from http://bit.ly/10lX3OR on 15 Sep 2014.

[26] Algethami S., 2013, More UAE professionals using Linkedin, Gulf News, retrieved from http://bit.ly/10lXdpu on 7 Sep 2014.

[27] Jones E., 2014, LinkedIn reveals most influential UAE brands, The National, retrieved from http://bit.ly/1sYPTrS on 4 Sep 2014.

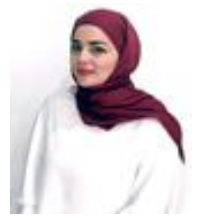

I.Iman was born in Abu Dhabi in 1988.

Educational Background:

Bachelor of Computer Science at Abu Dhabi

University, Abu Dhabi, UAE in Jan 2011

Major Computer Science

Minor Business Administration

Master Degree in Media and Communication at University of Wollongong, Dubai, UAE, in Jan 2015

She has worked as E-marketing Administrator, at Khidmah, a property and facilities management solutions provider, in Abu Dhabi. Currently, she is working at Etisalat, as Social Media Specialist.

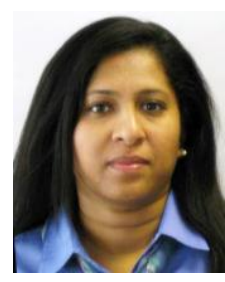

Dr S.Koshy is a Media and Communications professor at the University of Wollongong in Dubai. She is an award winning teacher and researcher, who is engaged in action-research on pedagogy with a focus on assessment methods. She has several media and marketing related publications and books to her credit. 